\title{
Cone-rod congenital amaurosis associated with congenital hypertrichosis: an autosomal recessive condition
}

\author{
I K JALILI* \\ From the Department of Clinical Ophthalmology, Moorfields Eye Hospital, London EC1V 2PD.
}

SUMmaRY Two female cousins were found to be affected with severe retinal dystrophy characterised by visual impairment from birth and profound photophobia in the absence of night blindness. Minimal fundus changes with a small foveal atrophy in the older cousin and slight macular pigment epithelial changes suggestive of early bull's eye appearance in the younger were detected, indicative of a cone-rod type of congenital amaurosis. This was associated with trichomegaly, bushy eyebrows with synophyrys, and excessive facial and body hair (including hypertrophied circumareolar hair on the breasts of the older cousin). The mode of inheritance appears to be autosomal recessive.

Congenital blindness from a retinal dystrophy was first reported by Leber ${ }^{1}$ in 1869 when he described a 'pigmentary retinopathy with congenital amaurosis'. He also recognised the familial nature of the condition and the role of consanguinity. ${ }^{2}$ Leber's congenital amaurosis represents a heterogeneous group of genetically determined conditions which share in common severe visual impairment at birth, or in the first year of life, coarse nystagmus, unrecordable electroretinogram, and variable age of onset of retinal and pigmentary degeneration, rather than a syndrome with different nosological entities as was believed by Krill and other workers. ${ }^{34}$ Excessively long eyelashes, large and bushy eyebrows with synophrys, and hypertrophied lanugo covering the entire body with a moustache and beard was reported by Broster ${ }^{5}$ in 1950 and is known as congenital generalised hypertrichosis. Gray ${ }^{6}$ in 1944 ascribed the term trichomegaly or 'movie lashes' to these abnormally long lashes.

The following two cases show an unusual combination of Leber's amaurosis and cone-rod dystrophy and congenital hypertrichosis (fig 1).

\section{Patients and methods}

The two cases, aged 18 and $12^{1 / 2}$ years when first examined, are maternal first cousins who were reviewed between October 1985 and August 1987 in

"Previously at St John's Ophthalmic Hospital, Jerusalem.

Received for publication 23 January 1989.

Accepted for publication 20 February 1989. a school for the visually handicapped and further investigated at St John's Ophthalmic Hospital, Jerusalem. They underwent full ophthalmic examination, electroretinography using the Neuropto system (Medelec UK) with full field stimulation (Ganzfield) and gold foil electrodes. ${ }^{7}$ Case 2 also had fundus fluorescein angiography.

\section{Case reports}

CASE 1 (V.47, FIG 2)

This female, aged 18 years when first examined, is the second of seven children of a maternal first cousin marriage. The paternal grandparents were paternal first cousins. Pregnancy was uneventful and the birth was normal and at term in hospital, birth weight $3250 \mathrm{~g}$. The patient's mother was born with a left segmented supernumerary kidney, and in the last five years she developed Raynaud's phenomenon, anaemia, and valvular heart disease with mild cardiac ischaemia.

In this sibship, the first child (V.46) died at the age of eight months from dehydration, and the eighth (V.53) is blonde with blue irides, unusual colouring in this family, who was found to be normal on examination. In addition, one sister (V.50) was said to be 'hairy' but had no visual problem. The rest of the sibs are normal.

CASE 2 (v.42, FIG 2)

This female was aged $12 \frac{1}{2}$ years when first seen. She is the fifth of eight children of healthy parents who 


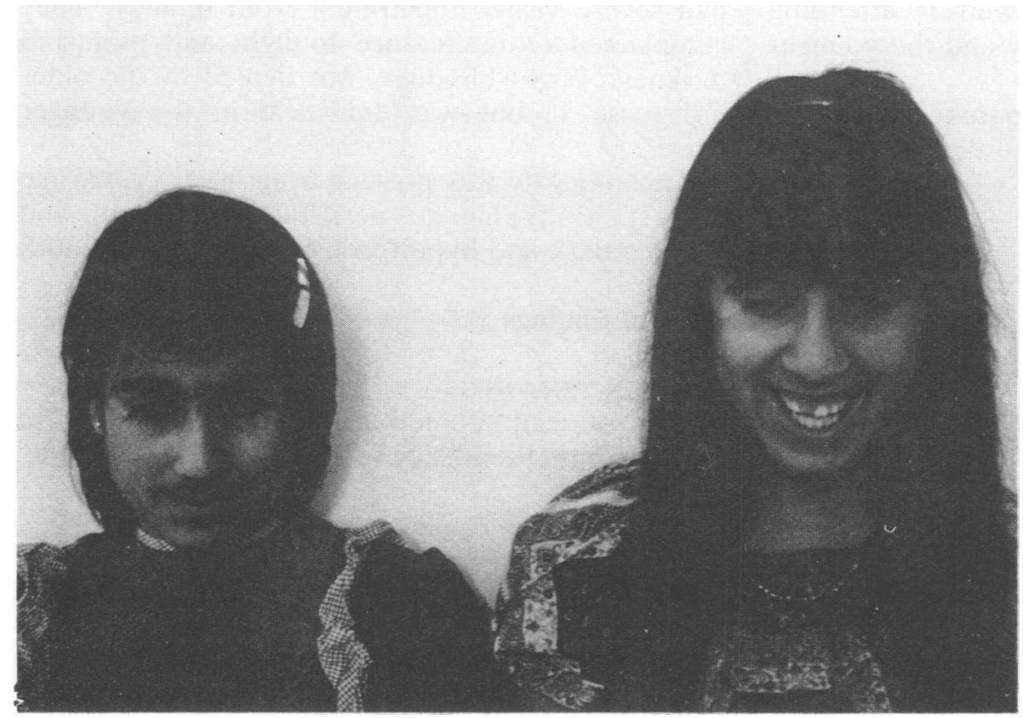

FIG 1 Two cousins affected with cone-rod congenital amaurosis. Left: the younger cousin (case 2) aged 12 years, shy and introverted. Right: the older cousin (case 1) aged 18 years, gifted musically.

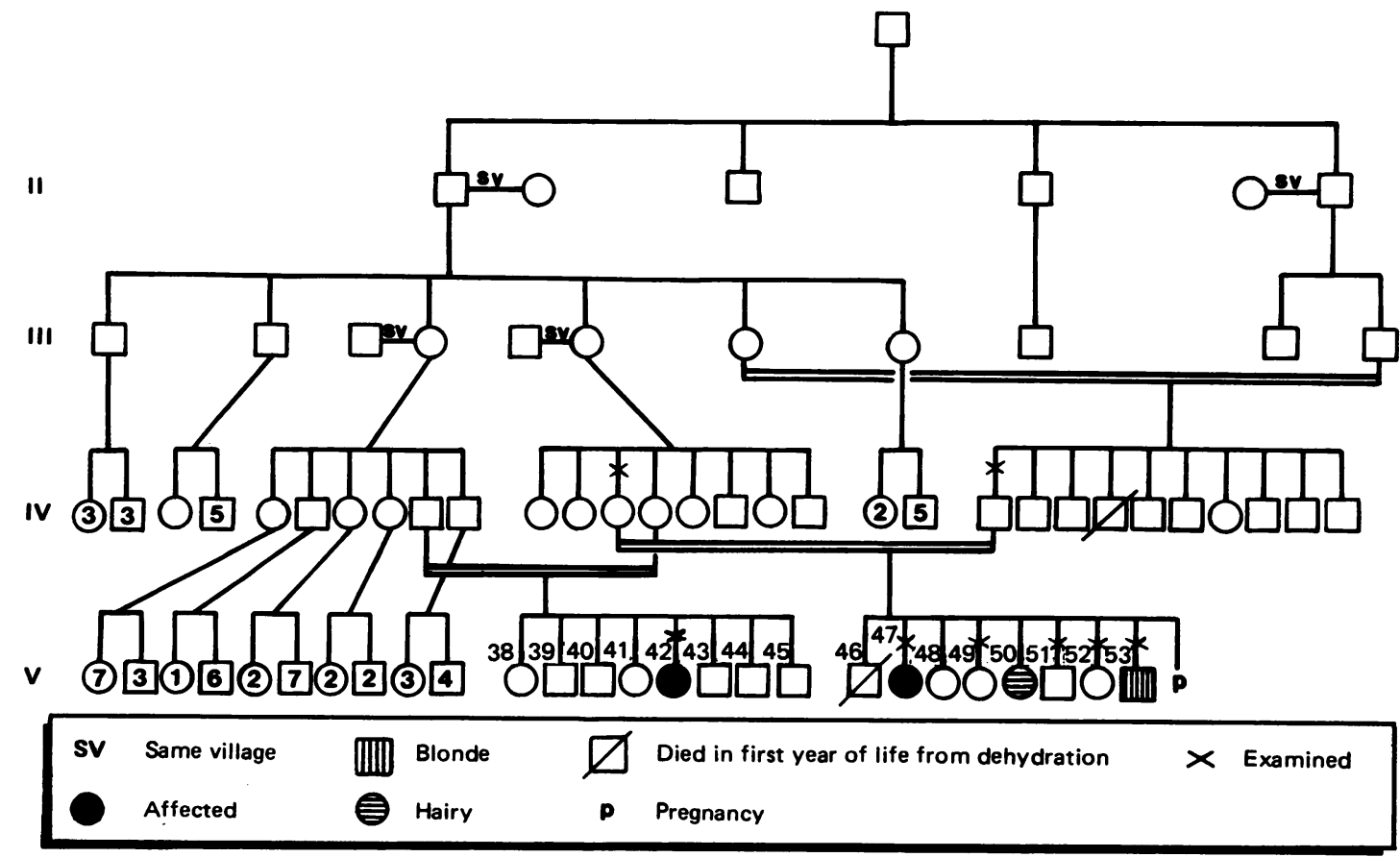

FIG 2 Family pedigree.

are also maternal first cousins and who live abroad with the remainder of the sibs. A history from the aunt indicated a normal' pregnancy and birth weight and no other cases of blindness in the rest of the sibs.
Both patients are otherwise healthy and menstruation started in both at the age of 13 . In early childhood, systemic examinations and investigations including EEG were normal and the prenatal history was negative. School performance was above average 
in both. The older (case 1), who is attending university, is also gifted musically and the younger (case 2) is shy and introverted.

Other than the paternal grandparents, there was no direct consanguinity (fig 2) but all the ancestors were from the same village.

\section{OPHTHALMIC HISTORY}

In both cases nystagmus and severe photophobia were first noted within a few weeks of birth and both

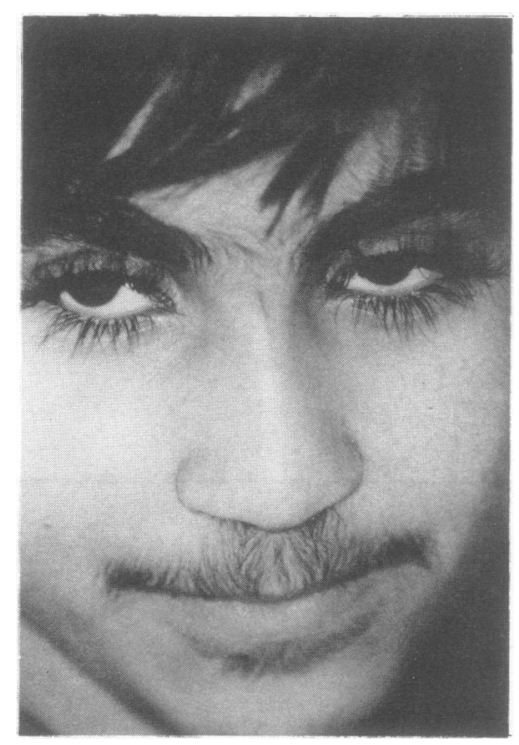

FIG 3 Case 2 showing trichomegaly, abundant facial hair with a moustache, and thick bushy eyebrows. had severe visual impairment from infancy. They complained of intolerance to light and preferred darkness. Night blindness was denied by the older girl (case 1) but was equivocal in the younger (case 2).

Trichomegaly was present from a very early age (fig 3). Body lanugo persisted after birth and became dark and hypertrophied later in childhood.

\section{Clinical findings}

OCULAR FINDINGS

Both cases had adopted a downward head posture and a habitual tendency to keep their eyes closed.

\section{Vision}

In both cases visual acuity was bare perception of light in a semi-bright room at $10 \mathrm{~cm}$, improving to 'hand movement' in a darkened room. They became totally incapacitated in the sunlight and, on previous hospital visits, vision was reported as 'no light perception' as it was normally tested in a bright room. Both patients were much more comfortable $\overrightarrow{0}$ and more able to navigate in the sun when wearing dark red tinted glasses. Both were hypermetropic (table).

\section{Ocular motility}

There was a pendular nystagmus which increased with the level of illumination, becoming rapid and searching in bright light. Ocular movements appeared full and pupillary reactions were sluggish in both cases.

The anterior segments showed no abnormality.

TABLE Comparison of clinical features between the previously reported five cases of retinal dystrophy associated with trichomegaly and the two cases discussed in this paper.

\begin{tabular}{|c|c|c|}
\hline & Refs 8 to 12 & This report \\
\hline Sex & $4 \mathrm{M}, 1 \mathrm{~F}$ & $2 \mathrm{~F}$ \\
\hline Age at examination & $2-37 y$ & 18 and $121 / 2$ y \\
\hline Eyelashes & Sparse & Dense, crowded, 2 to 3 rows \\
\hline Brows & Coarse/sparse & Coarse/bushy \\
\hline Hypertrophic lanugo & Not reported & Present \\
\hline Scalp hair & Alopecia & Dense, coarse hair \\
\hline Occipitofrontal bossing & Present & Absent \\
\hline Physical growth & Retarded & Normal \\
\hline Mental state & Varied from normal to moderate retardation & Normal, case 1 is musically talented \\
\hline Systemic disorders & Several & Absent \\
\hline Visual acuities & 6/60 LP & Perception of light* to hand movement $\dagger$ \\
\hline Refraction & ? to myopia $(-15 \cdot 00)$ & $\begin{array}{l}\text { Hypermetropia, case } 1+7.00 \mathrm{sph} /-3.00 \mathrm{cyl} \\
\quad \text { (axis, R:45, L:135) }\end{array}$ \\
\hline Fundus & $\begin{array}{l}\text { Choroidoretinal atrophy, pigmentary } \\
\text { degeneration on pale hypopigmented } \\
\text { background }\end{array}$ & $\begin{array}{l}\text { Case 1: foveal atrophy, case } 2 \text { : early bull's eye } \\
\text { maculopathy }\end{array}$ \\
\hline Consanguinity of parents & None & First cousin marriages \\
\hline
\end{tabular}

*In a semi-bright room. $\dagger=$ In a dim room. 


\section{Fundus}

The retinae showed faint pigment epithelial changes and in case 1 there was a small round area of foveal atrophy affecting the maculae and vascular tortuosity (fig 4a). Macular changes became more evident at a second examination 16 months later. In case 2 the maculae showed slight pigment epithelial disturbances suggestive of an early bull's eye lesion which was more pronounced in the left eye. The peripheral retinae and optic nerves appeared normal (figs $4 b, 5$ ).

OTHER FINDINGS

The faces of both cousins were covered by hyper- trophic lanugo with prominent moustaches (figs 1 and 3) and the older girl shaved her face frequently. Their eyebrows were bushy with synophrys and their hair was coarse. The eyelashes were long, dense, and crowded, arranged in two or three rows, and required regular trimming. Scalp hair was coarse and dense in case 1 but finer and lighter in colour in case 2 . Body hair was moderately dense all over the trunk and limbs and, in case 1, there was marked circumareolar hypertrichosis on both breasts (fig 6). The distribution of pubic hair was normal. There was no auditory impairment or any other systemic or dental anomaly.
FIG 4 Fundus photographs of the two cousins. Marked photophobia and nystagmus precluded good results. (a) Case 1: right eye showing a small area of foveal atrophy and venous tortuosity. (b) Case 2: left eye showing minimal fundus changes with faint spots of pigment epithelial atrophy in the macula suggestive of early bull's eye lesion. This was only detectable on high magnification using a diagnostic fundus contact lens. 


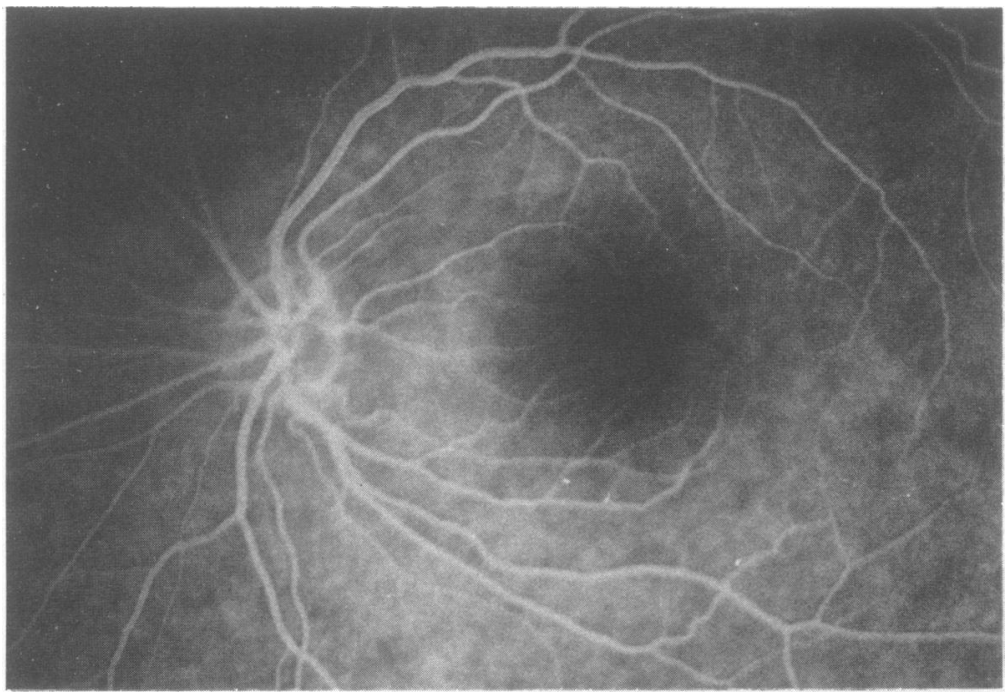

FIG 5 Fundus fluorescein angiography (FFA), left eye, in case 2 showing faint bull's eye lesion and widespread mottled hyperfluorescence.

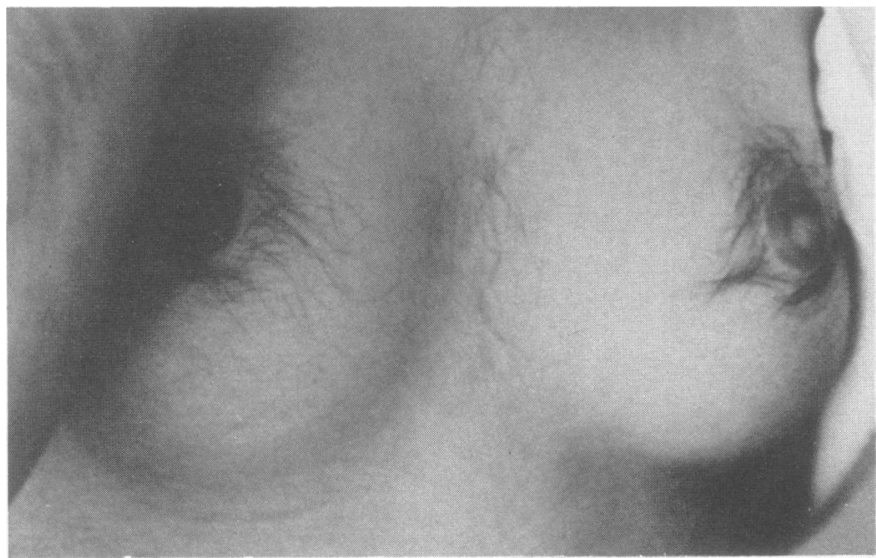

FIG 6 Photograph of the breast in case 1 at the age of 20 years showing circumareolar hypertrichosis.

\section{Investigations}

FUNDUS FLUORESCEIN ANGIOGRAM (CASE 2) (FIG 5)

Photophobia and nystagmus precluded good photographs. Angiography showed widespread, mottled hyperfluorescence and faint pigment epithelial defects over the maculae coinciding with those seen ophthalmoscopically.

\section{ELECTRORETINOGRAM (ERG) (FIG 7)}

The ERG, after 30 minutes of dark adaptation, was technically difficult owing to the trichomegaly, nystagmus, and photophobia. However, it was possible to obtain several tracings at various inten- sities of blue and white light. Photopic responses (white light flicker at $30 \mathrm{~Hz}$ ) were extinguished in both cases as were the scotopic responses in the $\mathrm{N}$ younger cousin (case 2 ). In case 1 , there was a barely recordable, delayed positive wave to blue and 0 white light stimulation which was reproducible.

\section{Discussion}

Leber's congenital amaurosis is an important cause $\stackrel{\text { ? }}{+}^{\circ}$ of congenital blindness and is characterised by $\frac{T}{T}$ severe visual impairment at birth or in the first year of life, nystagmus, and a wide array of ocular and

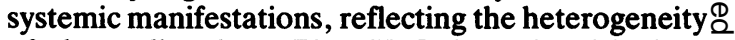
of these disorders. The ERG is extinguished oro 


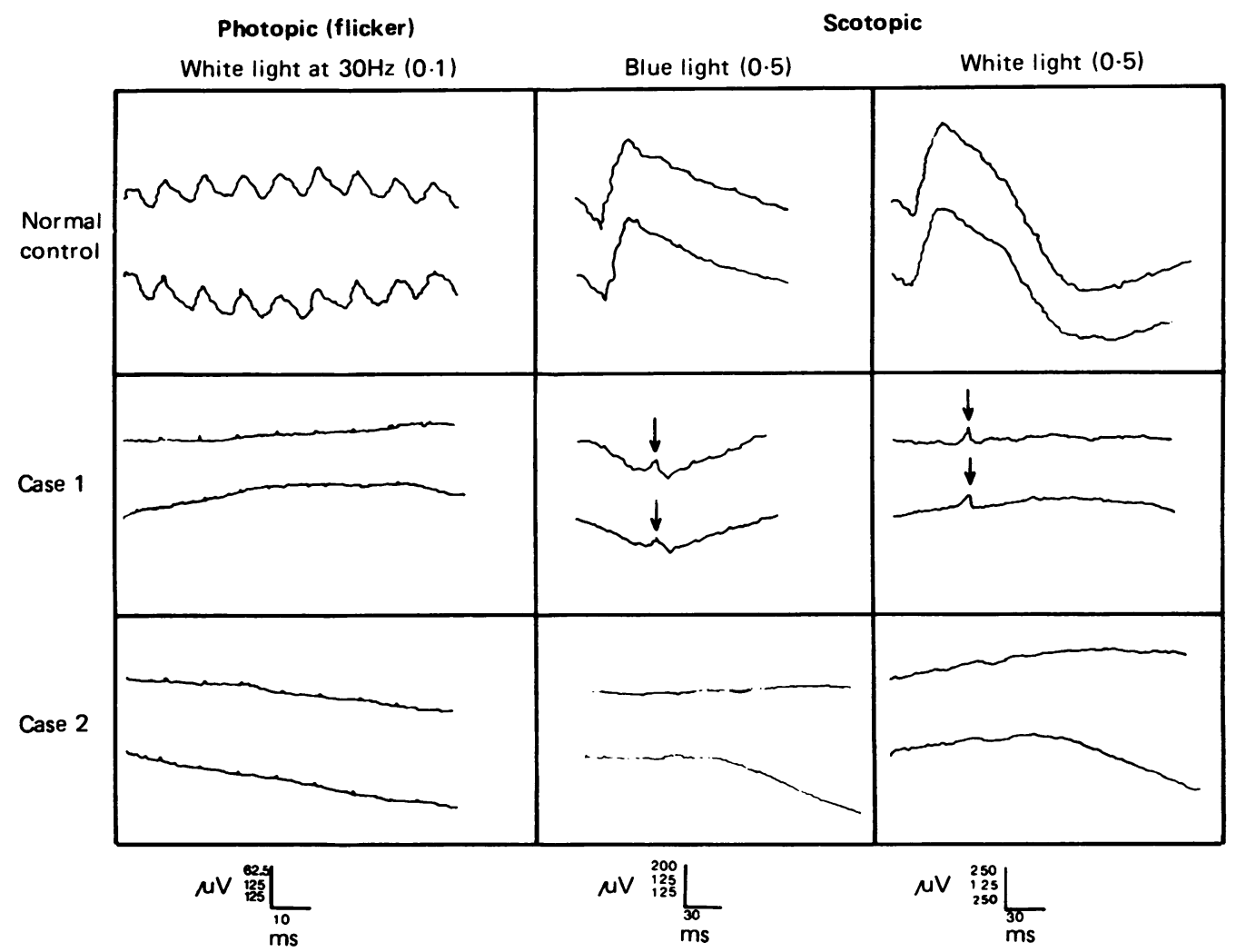

FIG 7 The electroretinogram (ERG). Top: normal control, middle: case 1, bottom: case 2. In each box the upper tracing is from the right eye and the lower from the left eye. Left column: photopic responses to a white light flicker at $30 \mathrm{~Hz}$ showing totally extinguished responses in both cases. Scotopic responses: middle column blue light and right column white light show a barely recordable positive response (arrow) at higher light intensities in case 1 but totally extinguished responses in case 2. (Numbers in parentheses indicate light intensity setting on the Ganzfield stimulator, Medelec UK.)

barely recordable. Night blindness is a feature of the condition but photophobia has been inconsistently and variably reported. Karel $^{13}$ found $73 \cdot 6 \%$ of his series of $\mathbf{4 2}$ patients suffered from photophobia of various degrees. However, Flynn and Cullen ${ }^{14}$ reported photophobia in one case (case 1) as did Heckenlively and Foxman. ${ }^{10}$ Jalili (in preparation) noted that photophobia was an insignificant feature in a series of approximately 120 patients with Leber's amaurosis and early onset retinitis pigmentosa; when photophobia was present, it was mild, of later onset, and only reported by patients on questioning. This was in contrast to the marked and striking photophobia which was a presenting feature and bitterly complained of by patients with cone and cone-rod dystrophies. ${ }^{16}$ This reflects the diversity of involvement of the various components of photoreceptors in this heterogeneous group of conditions.
In the two cousins reported here, the marked visual loss, sluggish pupillary reactions, unrecordable ERG, and the scarcity of ophthalmological changes given the duration of the disease points to a mixed retinal dystrophy resembling Leber's amaurosis with severe functional impairment. However, the presence of profound photophobia, macular changes similar to those previously reported in cone-rod disorders, ${ }^{17}$ and the absence of night blindness suggest the predominance of cone involvement. This appears to be relatively more severe in the younger cousin as shown by the marginally worse visual performance and the totally unrecordable ERG.

The history, clinical features, and investigations distinguish this condition from the other causes of congenital blindness: cortical blindness, optic atrophy, and rod monochromatism (achromatopsia). 
The latter is stationary with a visual acuity better than $3 / 60$, normal fundi, and scotopic ERG.

The association of trichomegaly and ocular abnormalities has seldom been reported; only seven cases have been described, five with retinal dystrophy ${ }^{8-12}$ and two with juvenile cataract and spherocytosis. ${ }^{18}$ Oliver and MacFarlane ${ }^{8}$ in 1965 were the first to describe a case of trichomegaly with pigmentary degeneration of the retina, mental and physical retardation, and mild hypothyroidism. These five sporadic cases differ from the two cousins described in this paper in several aspects (table).

The consanguinity and the inheritance pattern in the family reported here suggest an autosomal recessive mode of transmission.

In conclusion, these two cases represent a combination of a severe mixed receptor dystrophy with predominance of functional impairment of the photopic system associated with generalised hypertrichosis. It is suggested that the photophobia is significant and indicates a subgroup of 'cone-rod Leber's' in contrast to those with the marked night blindness and insignificant photophobia of 'rod-cone Leber's', existing in the wide array of conditions grouped under Leber's congenital amaurosis. These features in association with hypertrichosis have not been reported previously. 1920

I would like to thank Sir Stephen Miller and the Order of St John for providing the facilities and resources for this work, Professor Barrie Jay, Moorfields Eye Hospital for his advice and support during the preparation of this paper, and Mr Tony Moore, Addenbrooke's Hospital, Cambridge for examining the patients and for his encouragement. My thanks also to Dr Peter Qumri, Friends of the Patient Society, Bethlehem for providing the photograph of fig 6 and Misses Nefisa Jabr and Nawal El Baba for technical help.

\section{References}

1 Leber T. Ueber retinitis pigmentosa and angeborene amaurose. Albrecht von Graefes Arch Ophthalmol 1869;15:1-25.
2 Leber T. Ueber anomale formen der retinitis pigmentosa. Albrech von Graefes Arch Ophthalmol 1871;17:314-40.

3 Deutman AF. Rod-cone dystrophy. Clinical characteristics. In: Archer D, ed. Krills hereditary retinal and choroidal diseases. Vol 2. Hagerstown: Harper \& Row, 1977:552-76.

4 Franceschetti A, Francois J, Babel J. Autosomal chorioretinal heredodegenerations with tapetoretinal predominance. In: $\overrightarrow{\mathbb{D}}$ Chorioretinal heredodegenerations. Springfield, Illinois: Charles C Thomas, 1974:305-25.

${ }^{5}$ Broster LR. Hypertrichosis: a report of three cases. $\mathrm{Br} \mathrm{Med} \mathrm{J}$ 1950;1:1171-4.

6 Gray H. Trichomegaly or movie lashes. Stanford Med Bull 1944;2:157-8.

7 Arden GB, Carter RM, Hogg C, Siegal IM, Margolis G. Goldfoil electrode: extending the horizons for clinical electrical $\overline{3}$ retinography. Invest Ophthalmol Vis Sci 1979;18:421-6.

8 Oliver GL, McFarlane DC. Congenital trichomegaly with ${ }^{\circ}$ associated pigmentary degeneration of the retina, dwarfism and $\infty$ mental retardation. Arch Ophthalmol 1965;74:169-71.

${ }^{9}$ Cant SJ. Ectodermal dysplasia. J Pediatr Ophthalmol 1967;4: 13-17.

10 Corby DG, Lowe RS, Haskin RC. Hebertson LM. Tricho- 음 megaly, pigmentary degeneration and growth retardation. $A m J$ Dis Child 1971;121:344-5.

1 Delleman JW, Van Walbeek K. The syndrome of trichomegaly, tapetoretinal degeneration and growth disturbances. Ophthalmologica 1975;171:313-5.

12 Patton MA, Harding AE, Baraitser M. Congenital trichomegaly,

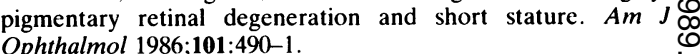

13 Karel I. Clinical picture of congenital diffuse tapetoretinal degeneration in 42 cases. Acta Univ Carol [Med] (Praha) 1969;15:259-335

14 Flynn JT, Cullen FC. Disc edema in congenital amaurosis of $\frac{\partial}{0}$ Leber's. Br J Ophthalmol 1975;59:497-502.

15 Heckenlively JR, Foxman SG. Congenital and carly-onset forms $\frac{\text { Dे }}{\mathrm{Q}}$ of retinitis pigmentosa. In: Heckenlively JR, ed. Retinitis pigmentosa. Philadelphia: Lippincott, 1988:114.

16 Jalili IK. Smith NJD. A progressive cone-rod dystrophy and amelogenesis imperfecta: a new syndrome. J Med Genet 1988;25:738-40.

17 Krill AE, Deutman AF, Fishman M. The cone degenerations. Doc Ophthalmol 1973;35:1-80.

18 Goldstein JH, Hutt AE. Trichomegaly, cataract, and hereditary spherocytosis in two siblings. Am J Ophthalmol 1972;73:333-5.

19 McKusick VA. Mendelian inheritance in man. 7th ed. Baltimore: 3 Johns Hopkins University Press, 1986.

20 Winter RM, Baraitser M, Douglas JM. Computerised database for the diagnosis of rare syndromes. J Med Genet 1984;21:121-3.

Correspondence to Mr I K Jalili FRCS, Professorial 9 Unit, Moorfields Eye Hospital, City Road, London? EC1V 2PD. 